\title{
Optimal Design of Steel Curved Roof Frames by Enhanced Vibrating Particles System Algorithm
}

\author{
Ali Kaveh ${ }^{1 *}$, Seyed Rohollah Hoseini Vaez², Pedram Hosseini ${ }^{3}$, Mohsen Bakhtiyari² \\ ${ }^{1}$ Centre of Excellence for Fundamental Studies in Structural Engineering, \\ School of Civil Engineering, Iran University of Science and Technology, \\ Narmak, Tehran-16, Iran \\ 2 Department of Civil Engineering, Faculty of Engineering, \\ University of Qom, Qom, Al-Ghadir Blvd, 3716146611, Iran \\ ${ }^{3}$ Faculty of Engineering, \\ Mahallat Institute of Higher Education, Markazi, Khomein-Mahallat Rd, 3781151958, Iran \\ *Corresponding author, e-mail: alikaveh@iust.ac.ir
}

Received: 07 August 2019, Accepted: 19 August 2019, Published online: 17 September 2019

\begin{abstract}
The paper presents an optimal design of steel curved roof frames with its roof being part of a circular arc. The elements of frames are tapered I-section members. In the objective function for optimization, two factors affecting the weight of frames are considered simultaneously. First, the roof slope angle as an effective variable on the values of the structural loading and second, the cross-section of members that are considered as continuous and discrete variables, respectively. In the range of 3 to 70 degrees, the optimum range of roof slope angles for steel curved roof frames, as well as precise value of the best roof slope angle, will be reported. Enhanced Vibrating Particles System (EVPS) algorithm is utilized for the optimal design of steel curved roof frames with tapered members. The performance and efficiency of the EVPS algorithm is compared with six other recently developed optimization algorithms including VPS, GWO, HS, SSA, ECBO and GOA algorithms. The effectiveness and performance of EVPS algorithm is proven. Frames design are performed using ANSI/AISC 360-05 specifications which strength, displacement and stability constraints are imposed on the frames.

\section{Keywords}

curved roof frames, tapered members, structural optimization, meta-heuristic algorithms, enhanced vibrating particles system algorithm

\section{Introduction}

Pitched roof steel frames are used in a wide range of span lengths that are usually considered as low-rise buildings. Pitched roof steel frames with tapered members are used in the construction of single-story building structures such as factories, warehouses, gymnasiums, hypermarkets, hangars, etc.

Members of the sloped roof frames can be prismatic with constant cross-section or non-prismatic with variable cross-section along the member [1]. Utilization of the tapered members makes it possible to strengthen parts of the member which are under larger stress resultants $[2,3]$. Pitched roof frames have different types and can be categorized as: gable frames, saw tooth frames, lean-to frames, mono slope frames, T-shape frames, domed frames, etc. [4]. Since there are always some limitations in resources, fund and time, optimization of these problems is an appropriate solution with regard to the limitations to achieve an ideal result [5]. Many studies are presented on the optimization of pitched roof steel frames. Saka [6] has introduced an optimal design method of pitched roof steel frames with haunches for the rafters based on Genetic Algorithm (GA).

Kravanja and Zula [7] and Kravanja et al. [8] studied design optimization of single-story steel building structures based on mixed- integer non-linear programming (MINLP) optimization. McKinstray et al. [9] have carried out the optimal design of long-span portal frames using fabricated beams based on Genetic Algorithm (GA). McKinstray et al. [10] have performed optimal design of steel portal frames taking into account rolled, fabricated and tapered sections by using Genetic Algorithm (GA). Kaveh et al. [11, 12] studied optimal design of single onesapn and multi-span pitched roof frames with tapered 
members by some recent meta-search algorithms. Most of the researches of the past are in the field of pitched roof steel frames. Curved roof frames are the other types of pitched roof frames.

These frames are a good option for replacing regular rectangular frames. One aspect of the applications of curved members is related to our aesthetic attitude. Curved members can provide a suitable theme for innovative design in the construction of steel structures [13]. Such frames can be considered as barrel vault space structures with identical usages.

Vanderplaats and Han [14] considered the arches shape optimization and areas of the members with hinged and fixed ends. They minimized the volume of the structure by changing areas of the members and the coordinates of the nodes on the arches using the approximate force method. Taisy et al. [15] presented an optimization method for minimizing the weight and strain energy of arched structures. If the curved roof frames are shaped properly, they can be a good economic solution for a wide range of span lengths and more load-carrying capacity for a certain volume of material [15]. One of the most important objects in the curved elements is selecting its appropriate slope angle.

The main purpose of the present study is to achieve the optimum member sections and optimum range of roof slope angles in a two-dimensional design of the symmetric steel curved roof frames. The frame elements have web tapered members. Choosing the right sections at the beginning and end of each element is one of the most efficacious issues in designing web tapered members. The optimization variables are the cross-sections at the beginning and end of the elements of frames. Also, the slope angle of the curved roof frames is considered as one of the optimization variables. The value of this variable is efficacious in the value of loads applied on the frames. The used design method and structural loading are in accordance with ANSI/AISC 360-05 specifications [16] and ASCE 7-10 standard [17].

In order to optimal design of frames, the EVPS algorithm is used. EVPS algorithm is an enhanced version of the Vibrating Particles System (VPS) algorithm, proposed by Kaveh et al. [18]. The obtained results of this algorithm have been compared with some population-based optimization methods such as Vibrating Particles System (VPS) [19], Grey Wolf Optimizer (GWO) [20], Harmony Search (HS) [21], Salp Swarm Algorithm (SSA) [22], Enhanced Colliding Bodies Optimization (ECBO) [23], and Grasshopper Optimisation Algorithm (GOA) [24].
The rest of the study is structured as follows: In Section 2, the modeling of a curved roof is presented. The objective function, problem constraints, and its mathematical formulation is described in Section 3. In Section 4, the structural loading is presented. A short description of utilized algorithms is provided in Section 5. In Section 6, design examples are presented. Finally, Section 7 concludes the study and suggests some directions for future studies.

\section{Curved roof modeling}

In this paper, to shape the curved roof frames, straight short elements with tapered members are used. Choosing the number of straight segments to model a curved member mainly depends on its curvature. As a guide, for a semicircular member (meaning $\gamma=180^{\circ} ; \gamma$ is the angle that connects arc center to the point first and the end of the arc; $\gamma$ is shown in Fig. 1) converting the arc with five straight segments gives a rather coarse model, ten straight segments leads a logical model and twenty straight segments provides a very good model [13].

The guidance mentioned above is the number of straight segments for a complete semicircular member. But the curved members can be any part of the perimeter of a circle with any radius. The curvature of the roof is considered to be part of a circular arc with eight straight segments in accordance with Fig. 1. Roof slope angle $(\theta)$ is one of the optimization variables which is considered as the slope of the tangent line on the circular arc of the roof. $\theta$ is shown in Figs. 1-2. The range of roof slope angle variations is considered continuously from 3 to 70 degrees.

The central points of all sections at the starting and ending segments of the roof are placed on the defined circular arc. According to the defined guide for the number of the straight segments, in this problem for the roof slope angle between 3 to 36 and 36 to 70 degrees a logical model and a very good model is provided, respectively. In the next section an idealized model of a steel curved roof frame is considered.

\subsection{Determination of the coordinates of the points}

In accordance with Fig. 2 and Eq. (1), the radius of the circular arc $(R)$ is determined first by considering selected slope angle of the circular arc for the roof $(\theta)$. Then, according to the coordinates of points located on the circular arc, the coordinates of points, relative to the origin of coordinates is determined according to Eq. (2):

$R=(r / 2) \cos (90-\theta)$, 
$Y=\sqrt{X^{2}-R^{2}}$

where $L$ is the length of the span.

\section{Formulation of the problem}

Optimal design of frame structures is often carried out by considering the constraints surrounding structural performance with the purpose of minimizing an objective function:

$$
\begin{array}{ll}
f_{i}(x) \leq 0 & i=1,2, \ldots, p, \\
g_{i}(x) \leq 0 & j=1,2, \ldots, q, \\
h_{k}^{\min }(x) \leq h_{k}(x) \leq h_{k}^{\max } & k=1,2, \ldots, r,
\end{array}
$$

where $f_{i}(x), g_{j}(x)$ and $h_{k}(x)$ are thee inequality constraints, equality constraints and acceptable range for constraints, respectively.

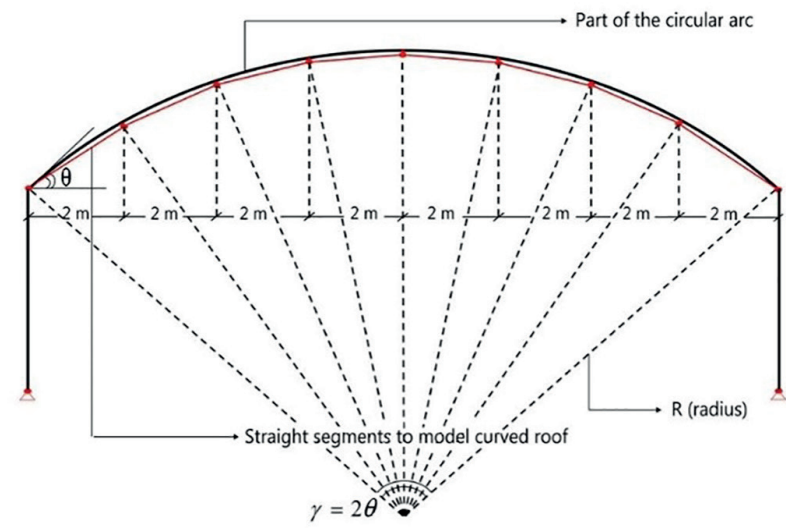

Fig. 1 Number of straight segments to model curved roof

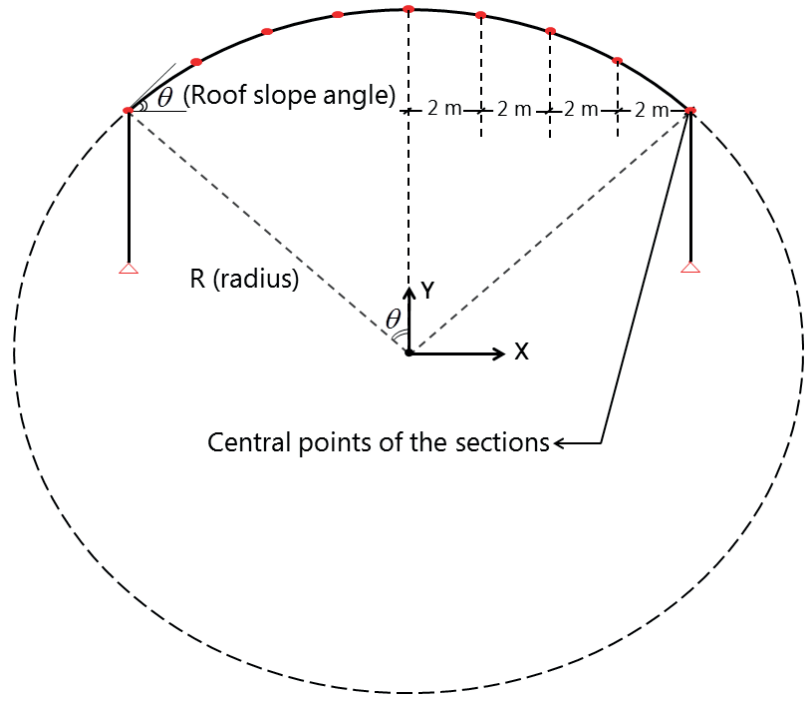

Fig. 2 The coordinates of the central points of the sections located on the circular arc

\subsection{Objective function}

Objective function is taken as the total weight of the structure, which is calculated as follows (Eq. (4)):

$\operatorname{Cos} t_{i n i}=\sum_{i=1}^{n} \rho \bar{A}_{i} L_{i}$,

where $\rho$ denotes the steel density equal to $7850 \mathrm{~kg} / \mathrm{m}^{3}, \bar{A}_{i}$ is the average of the beginning and the end of cross-section areas of the $i$ th segment and $L_{i}$ is the length of the $i$ th segment of the portal frame structure and $n$ is the total number of segments in the steel curved roof frame.

\subsection{Design constraints}

\subsubsection{Strength constraints}

According to ANSI/AISC 360-05 (AISC 2005), the following conditions must be checked for all sections:

$\left\{\begin{array}{lc}\frac{P_{u}}{2 f_{c} P_{n}}+\frac{M_{u}}{f_{b} M_{n}}-1 £ 0 & \text { for } \frac{P_{u}}{f_{c} P_{n}}<0.20 \\ \frac{P_{u}}{f_{c} P_{n}}+\frac{8 M_{u}}{9 f_{b} M_{n}}-1 £ 0 & \text { for } \frac{P_{u}}{f_{c} P_{n}}{ }^{3} 0.20\end{array}\right.$,

where $P_{u}$ is the required axial strength (tension or compression); $P_{n}$ is the nominal axial strength (tension or compression); $\phi_{c}$ is the resistance factor $\left(\phi_{c}=0.9\right.$ for tension and compression); $M_{u}$ is the required flexural strength; $M_{n}$ is the nominal flexural strength; and $\phi_{b}$ is the flexural resistance reduction factor $\left(\phi_{b}=0.9\right)$.

In calculation of $M_{n}$ in this study, $C_{b}$ (lateral torsional buckling modification factor) is conservatively considered as 1.0 (according to the code) for all cases. Also in calculating $P_{n}, K$ (effective length factor) is assumed to be 1.0.

\subsubsection{Maximum vertical displacement}

Maximum vertical displacement is calculated as (Eq. (6)):

$\frac{\Delta_{V}}{L}-R_{V} \leq 0$,

where $\Delta_{V}$ is the maximum vertical displacement of apex; $L$ is the span length of the curved frame; and $R_{V}$ is the allowable vertical displacement index which is equal to $1 / 360$ and 1/240 under dead and live loading, respectively.

\subsubsection{Maximum horizontal displacement}

Maximum horizontal displacement is calculated as follows (Eq. (7)):

$\frac{\Delta_{H}}{H}-R_{H} \leq 0$ 
where $\Delta_{H}$ is the maximum horizontal displacement of the eaves point in the curved frame; $H$ is the height of the column; $R_{H}$ denotes the allowable horizontal displacement index which is considered as H/200 under lateral loads.

\subsubsection{The buckling constraints}

According to the ANSI/AISC 341-10 (AISC 2010) manual for design of slender compression elements, the reasonable and appropriate width-to-thickness ratios must satisfy the following conditions:

$b_{f} / t_{f} \leq 18$,

$h / t_{w} \leq 0.4 E / F_{y} \leq 260$.

\subsubsection{The stability constraint}

The stability constraints are defined in accordance with the ANSI/ AISC 360-10 [25] regulations. The P-delta effects create additional forces or moments in the members. The following equation (Eq. (10)) is considered as a stability index of the frame to take into account the effects of $P$-delta:

$\varphi=\frac{P_{x} \Delta I_{e}}{V_{x} h_{s x} C_{d}}$,

where $\varphi$ represents the stability coefficient, $P_{x}$ is the total vertical design load above level $x$ with a maximum load factor of 1.0 (kip or $\mathrm{kN}), \Delta$ is the design story drift occurring simultaneously with $V_{x}, I_{e}$ is the importance factor, $V_{x}$ is the seismic shear force acting between levels $x$ and $x-1, h_{s x}$ is the story height below level $x$, and $C_{d}$ is the deflection amplification factor. The upper bound of the stability coefficient $\left(\varphi_{\max }\right)$ is calculated as follows (Eq. (11)):

$\varphi_{\max }=\frac{0.5}{\beta C_{d}} \leq 0.25$,

where $\beta$ denote the ratio of shear demand to shear capacity for the story between levels $x$ and $x-1$. This ratio is permitted to be conservatively taken as 1.0. If the stability coefficient $(\varphi)$ of a structure is equal to or less than 0.10 , P-delta effects not required to be considered and the designer can ignore the second-order analysis. Where $\varphi$ is greater than 0.10 but less than or equal to $\varphi_{\max }$, the incremental factor related to $P$-delta effects on displacements and member forces should be determined by the rational analysis. Alternatively, it is permitted to multiply displacements and member forces by $1.0 /(1-\varphi)$. Where $\varphi$ is greater than $\varphi_{\max }$, the structure is potentially unstable and should be redesigned (AISC 2010). In this study, the deflection amplification factor $\left(C_{d}\right)$, is considered to be 4 due to the frame system. Also, the $P$-delta effect is considered on the seismic load combinations.

\section{Structural loading}

In this study, regulations of ASCE/SEI Standard 7-10 (ASCE/SEI 2010) is used for applying the dead, live, snow, wind and seismic loads. The load width of the frame is considered to be $6.0 \mathrm{~m}$. The live and snow loads are applied as gravity projection. The amount of loads applied on the frame depends on the roof slope angle and changes by changing the slope angle of the roof. Since in this paper, the roof slope angle is one of the selected optimization variables, the loading value is affected by this variable. The structural loading is presented in general. Also, in the continuation of each section, for the roof slope angle equal to 21.26 degree, the applied loads are presented with the exact values.

\subsection{Loading combinations}

Based on the specifications of ASCE 2010 [17], the following load combinations should be considered for designing structural members. The term of $0.2 \mathrm{~S}_{\mathrm{DS}} \mathrm{D}$ in load combinations 5 to 7 is considered in order to include the effects of the vertical seismic load.

$$
\begin{array}{ll}
\text { 1. } & 1.4 D \\
\text { 2. } & 1.2 D+1.6 L+0.5(S \text { or } R) \\
\text { 3. } & 1.2 D+1.6(S \text { or } R)+(L \text { or } 0.5 W) \\
\text { 4. } & 1.4 D+1.0 W+L+0.5(S \text { or } R) \\
\text { 5. } & (1.2+0.2) D+E+L+0.2 S \\
\text { 6. } & 0.9 D+1.0 W \\
\text { 7. } & (0.90 .2) D+E
\end{array}
$$

\subsection{The dead and collateral loads (D)}

The type of cladding is considered to be a metal sandwich panel. The cladding weight of the roof and purlins is considered as $14.64 \mathrm{~kg} / \mathrm{m}^{2}$ for the dead load. Summary of the dead load is presented in Table 1.

Table 1 Summary of the dead and live loading

\begin{tabular}{lccc}
\hline \multicolumn{2}{c}{ Dead loading } & \multicolumn{2}{c}{ Live loading } \\
\hline Dead load & $14.64\left(\mathrm{~kg} / \mathrm{m}^{2}\right)$ & Live load & $97.648\left(\mathrm{~kg} / \mathrm{m}^{2}\right)$ \\
Loading per & $6(\mathrm{~m})$ & Loading per & $6(\mathrm{~m})$ \\
Uniform dead & $87.84(\mathrm{~kg} / \mathrm{m})$ & $\begin{array}{c}\text { Uniform live } \\
\text { load }\end{array}$ & $585.89(\mathrm{~kg} / \mathrm{m})$ \\
load & & & \\
\hline
\end{tabular}

Table 2 Roof slope factor $\left(C_{s}\right)$ for curved roofs

\begin{tabular}{cc}
\hline Roof slope angle & $C_{s}$ \\
\hline $0-30$ & 1 \\
$30-70$ & $1-\left(\right.$ Slope $\left.-30^{\circ}\right) / 40^{\circ}$ \\
\hline
\end{tabular}




\subsection{The live load (L)}

According to the ASCE 7 Standard (ASCE 2010), the live load of a pitched roof is $97.65 \mathrm{~kg} / \mathrm{m}^{2}\left(20 \mathrm{lb} / \mathrm{ft}^{2}\right)$, and there is no concentrated load to check the rigid frames with. It is also assumed that the live load is not reducible. The live load information can be found in Table 1 .

\subsection{The balanced and unbalanced snow loads ( $S$ )}

The flat roof snow load, $P_{f}$, is calculated by using the following equation (Eq. (12)):

$$
P_{f}=0.7 C_{e} C_{t} I_{s} P_{g},
$$

where the exposure factor, $C_{e}$, thermal factor, $C_{t}$, and importance factor, $I_{s}$, are taken as 1.0 based on sections 7.3.1 through 7.3.3 of ASCE/SEI 7-10 regulations. The ground snow load, $P_{g}$, obtained per site-specific analysis is equal to $97.65 \mathrm{~kg} / \mathrm{m}^{2}\left(20.0 \mathrm{lb} / \mathrm{ft}^{2}\right)$; thus: $P_{f}=14 \mathrm{psf}$.

In accordance with sections 7.4.3 and 7.6.2 in ASCE/ SEI 7-10 the balanced and unbalanced snow loads shall be determined according to the loading diagrams in Figs. 7-3 of the code. These diagrams are illustrated in Fig. 3.

$C_{s}$ is the roof slope factor and its calculation are listed in Table 2 in accordance with the Figs. 7-2 or Chapters 7-4 of the regulation ASCE/SEI 7-10. In calculating $C_{s}$ is assumed that the surfaces are unobstructed slippery. In Fig. $3, C_{s}^{*}$ and $C_{s}^{* *}$ are the $C_{s}$ for the slope of eave point and 30 degrees slope, respectively. For the roof slope of $21.26^{\circ}$, value of balanced and unbalanced snow loads shown in Fig. 4.

According to the section 7.6.2 of ASCE/SEI 7-10 regulations if the roof slope angle of a straight line from the eaves (or the $70^{\circ}$ point, if present) to the crown is less than $10^{\circ}$ or greater than $60^{\circ}$, unbalanced snow loads shall not be taken into account.

\subsection{The seismic load (E)}

The seismic base shear, $V$, in a given direction is calculated according to the following equation (Eq. (13)):

$V=C_{S} W$,

where $C_{s}$ and $W$ are the seismic response coefficient and the effective seismic weight, respectively. The seismic response coefficient, $C_{s}$, is calculated as:

$$
C_{S}=\frac{S_{D S}}{R S I_{e}},
$$

where $S_{D S}$ is the design spectral response acceleration parameter in the short period range, $R$ is the response modification factor and $I_{e}$ is the importance factor. Since the
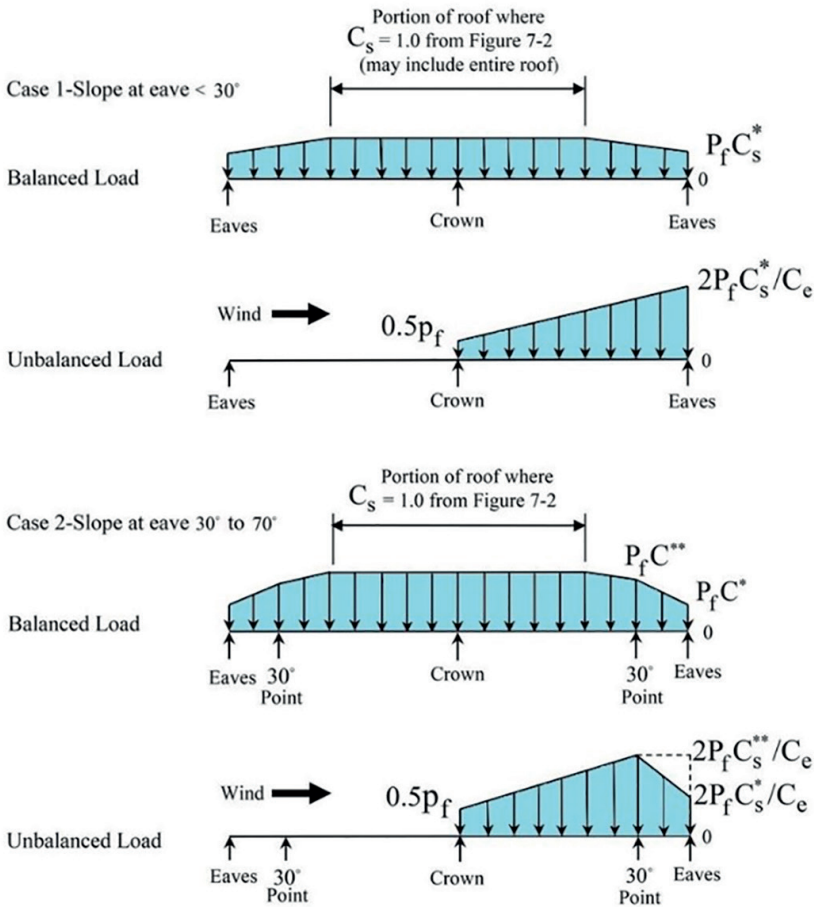

Fig. 3 Balanced and unbalanced snow loads for curved roofs

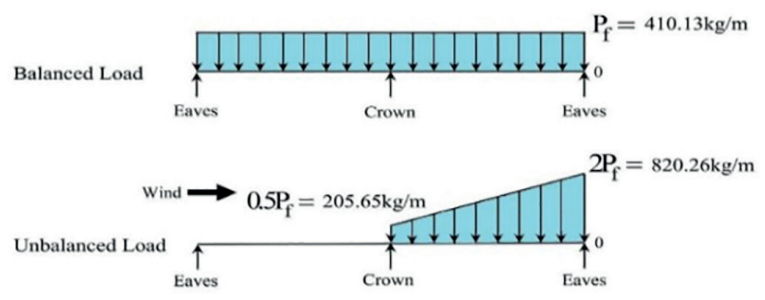

Fig. 4 Balanced and unbalanced snow loads for the roof slope angle equal to $21.26^{\circ}$

location of this study is assumed to be Clay county Kansas in the USA, the mapped Risk-Targeted Maximum Considered Earthquake (MCER) spectral response acceleration parameter for short periods $\left(S_{S}\right)$ and the mapped MCER spectral response acceleration parameter at a period of $1 \mathrm{~s}\left(S_{1}\right)$ are as $17 \%$ and $5 \%$, respectively. Then, the $S_{D S}$ values are evaluated as 0.2768 . The summarized calculation of the $C_{S}$ parameter is presented in Table 3 .

\subsection{The wind loads $(W)$}

For evaluating the wind load for a low rise building, the wind pressure is calculated as the (Eq. (15)):

$q_{z}=0.613 K_{z} K_{z t} K_{d} V^{2} \quad\left(N / m^{2}\right)$,

where $K_{z}$ is the velocity pressure exposure coefficient, $K_{z t}$ is the topographic factor, $K_{d}$ is the wind directionality factor, and $V$ is the basic wind speed. These parameter values are used in this study: $K_{z}=0.89, K_{d}=1,0.85$ and $V=90 \mathrm{mph}(40.234 \mathrm{~m} / \mathrm{s})$. 
Table 3 The summarized calculation of $C_{S}$

\begin{tabular}{cc}
\hline$S_{D S}$ & 0.2768 \\
$R$ & 4.5 \\
$I_{e}$ & 1 \\
$\left(C_{S}\right) \max$ & 0.041 \\
$\left(C_{S}\right) \min$ & 0.01 \\
$S_{D S} / R I_{e}$ & 0.079 \\
then $C_{S}=$ & 0.041 \\
\hline
\end{tabular}

$q_{h}$ is the velocity pressure at $h$ height (roof average height), which corresponds to the Eq. (16):

$q_{h}=0.613 K_{h} K_{z t} K_{d} V^{2} \quad\left(N / m^{2}\right)$.

According to Table 27.3-1 in ASCE 7-10, $K_{h}$ is equal to:

$K_{h}=2.01\left(\frac{h}{274.32}\right)^{\frac{2}{9.5}} \quad$ in metric

where $h$ is the average height of the roof. The parameter $K_{h}$ is a function of the average height of the roof, whose value changes by changing in the slope of the roof. The design wind pressures for the frame system of an enclosed and partially enclosed rigid building at all heights, is determined by the Eq. (18):

$$
P=q G C_{P}-q_{i}\left(G C_{P i}\right),
$$

where:

$q=q_{z}$ for the windward wall evaluated at height $z$ above the ground.

$q=q_{h}$ for the leeward wall, side walls, and roof, evaluated at height $h$.

$q_{i}=q_{h}$ for the windward wall, side walls, leeward wall, and roof of enclosed buildings and for negative internal pressure evaluation in partially enclosed buildings.

$q_{i}=q_{z}$ for the positive internal pressure evaluation in partially enclosed buildings where height $z$ is defined as the level of the highest opening in the building that could affect the positive internal pressure. For positive internal pressure evaluation, $q_{i}$, may conservatively be evaluated at height $h$.

$G=$ gust-effect factor $(=0.85)$.

$G_{P}=$ external pressure coefficient.

$\left(G C_{P i}\right)=$ internal pressure coefficient $= \pm 0.18$.

for the roof slope equal to 21.26 degrees:

$q_{z}=15.834 \mathrm{psf}\left(77.309 \mathrm{~kg} / \mathrm{m}^{2}\right)$

$q_{h}=16.232 \mathrm{psf}\left(79.252 \mathrm{~kg} / \mathrm{m}^{2}\right)$

$q_{i}=16.232 \mathrm{psf}\left(79.252 \mathrm{~kg} / \mathrm{m}^{2}\right)$

Rise-to-Span ratio $(r)=1.5015 / 160.0938$
Table 4 The coefficient of $C_{p}$ in two orthogonal directions of wind for arched roofs

\begin{tabular}{lccc}
\hline $\begin{array}{l}\text { Rise-to-Span } \\
\text { Ratio, } r\end{array}$ & $\begin{array}{c}\text { Windward } \\
\text { quarter }\end{array}$ & $\begin{array}{c}C_{p} \\
\text { Center } \\
\text { half }\end{array}$ & $\begin{array}{c}\text { Leeward } \\
\text { quarter }\end{array}$ \\
\hline $0<r<0.2$ & -0.9 & $-0.7-r$ & -0.5 \\
$0.2 \leq r<0.3^{*}$ & $1.5 \mathrm{r}-0.3$ & $-0.7-r$ & -0.5 \\
$0.3 \leq r \leq 0.6$ & $2.75 \mathrm{r}-0.7$ & $-0.7-r$ & -0.5 \\
\hline
\end{tabular}

*When the rise-to-span ratio is $0.2 \leq r \leq 0.3$, alternate coefficients given by $6 r-2.1$ shall also be used for the windward quarter

(Rise: see Fig. 8). External pressure coefficients $\left(C_{p}\right)$ are listed in Table 4. According to the Table 4, values of parameter $C_{p}$ for windward quarter, center half and leeward quarter are equal to $-0.9,-0.7938$ and -0.5 , respectively. The values of two cases of wind loading on the curved frame are illustrated in Figs. 5 and 6.

\section{Optimization algorithms}

In recent years, metaheuristic algorithms have been considered and expanded due to their effectiveness and efficiency in solving optimization problems in engineering science some of these are as follows:

Nazari-Heris et al. [26], Zhao et al. [27], Sameer et al. [28], Reddy et al. [29], Stützle et al. [30], Pijarski and Piotr [31], Yapici and Cetinkaya [32], Dede et al. [33], Grzywiński et al. [34], Kaveh et al. [35], Kaveh et al. [36] and Kaveh and Ilchi Ghazaan [37].

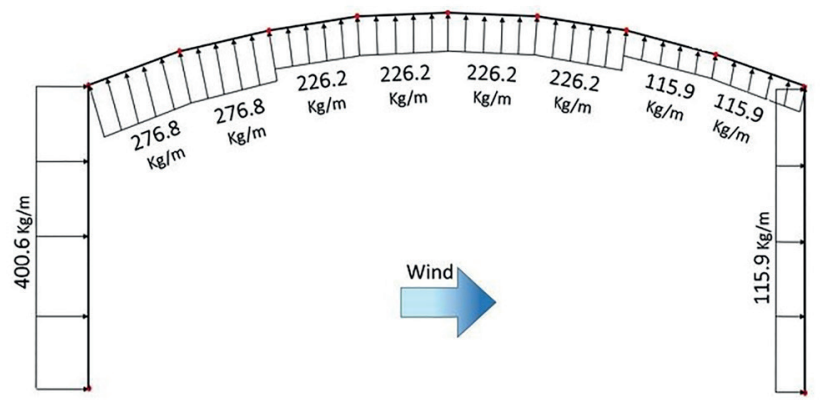

Fig. 5 Case 1 wind load on the steel curved roof frame

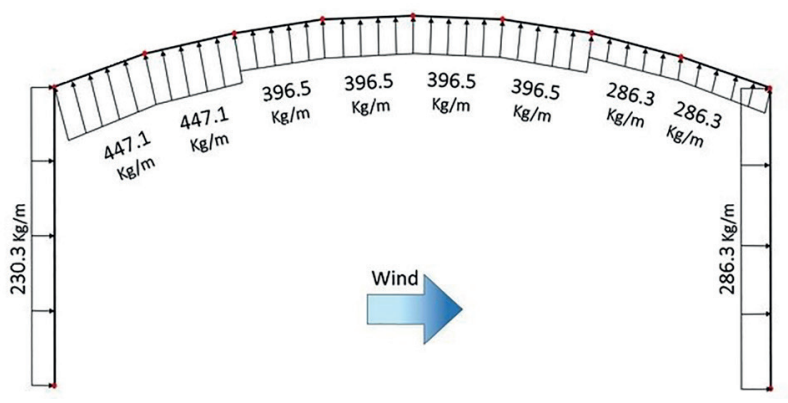

Fig. 6 Case 2 wind load on the steel curved roof frame 
Following a description of the EVPS algorithm with a brief description of six other metaheuristic algorithms including VPS, GWO, HS, SSA, ECBO and GOA algorithms, is presented in the following subsections.

\subsection{Vibrating Particles System}

Vibrating particles system is a population-based algorithm that resembles a vibrational single degree of freedom system with a viscous damping [19]. Particle quality gradually improves by using randomness and utilization of the results so that the particles approach their equilibrium positions.

To achieve the answer, three batches of particles are produced. The three produced batches of particles include the historically best position of the entire population $(H B)$, good particle $(G P)$ and bad particle $(B P)$. After the current population is arranged in accordance with the value of the objective function and ascending, GP from the first half and $B P$ from the second half are randomly selected. In this algorithm, generating new responses is conducted by the Eqs. (19)-(22):

$$
\begin{aligned}
& X_{i}^{j}=\omega_{1}\left[\text { D.A.rand } 1+H B^{j}\right] \\
& +\omega_{2}\left[\text { D.A.rand } 2+G P^{j}\right]+\omega_{3}\left[\text { D.A.rand } 3+B P^{j}\right] \\
& A=\left[\omega_{1}\left(H B^{j}-X_{i}^{j}\right)\right]+\left[\omega_{2}\left(G P^{j}-X_{i}^{j}\right)\right]+\left[\omega_{3}\left(B P^{j}-X_{i}^{j}\right)\right] \\
& \omega_{1}+\omega_{2}+\omega_{3}=1 \\
& D=\left(\frac{\text { iter }}{\text { iter }}\right)_{\text {max }}^{-\alpha}
\end{aligned}
$$

where $X_{i}^{j}$ is the $j$ th variable of the $i$ th particle and $\omega_{1}, \omega_{2}$ and $\omega_{3}$, are three factors for measuring the relative importance of the $H B, G P$ and $B P$ particles, respectively. Here, iter is the current iteration number and iter $_{\max }$ is the total number of iterations. $\alpha$ is a constant coefficient and it is equal to 0.05 in this study, $D$ is a parameter for measuring the effect of the damping level on the vibration. rand 1 , rand 2 and rand 3 are random numbers of uniform values in the range of $[0,1]$. Applying or not applying the effect of $B P$ on particle update, is considered by a parameter such as $\rho$ in the range of $(0,1)$. If $\boldsymbol{\rho}<$ rand, then $\omega_{\mathbf{3}}=\mathbf{0}$ and thence $B P$ does not have any effect on the particle update.

\subsection{Enhanced Vibrating Particles System}

Enhanced vibrating particles system is an enhanced version of VPS algorithm. This improvement increases the convergence speed and augments the search ability, assists EVPS to escape local optima and generally leads to better results [18]. In the EVPS, $H B$ acts as a memory and stores the best experienced position of the entire population. This method has three differences compared to the VPS algorithm. The following equation replaces Eqs. (19)-(22) in the VPS algorithm:

$$
\begin{array}{r}
X_{i}^{j}= \begin{cases}{\left[\text { D.A.rand } 1+O H B^{j}\right]} & (a) \\
{\left[\text { D.A.rand } 2+G P^{j}\right]} & (b) \\
{\left[\text { D.A.rand } 3+B P^{j}\right]} & (c)\end{cases} \\
X_{i}^{j}= \begin{cases}( \pm 1)\left(O H B^{j}-X_{i}^{j}\right) & (a) \\
( \pm 1)\left(G P^{j}-X_{i}^{j}\right) & (b) \\
( \pm 1)\left(B P^{j}-X_{i}^{j}\right) & (c)\end{cases}
\end{array}
$$

where one of the equations of $(a),(b)$ or $(c)$, with the probability of $\omega_{1}, \omega_{2}$ and $\omega_{3}$ is used, respectively. $( \pm 1)$ is used randomly. $O H B$ parameter is one row of memory from the best-experienced position of the entire population that is randomly selected. Also, in this method, parameters $O H B, G P$ and $B P$ are independently determined for each particle.

\subsection{Gray Wolf Optimizer}

Gray Wolf Optimizer (GWO) was introduced by Mirjalili et al. [20], is a population-based algorithm inspired by the social and hierarchical behavior of wolves in the hunting mechanism. In this algorithm, four types of gray wolves, including alpha, beta, delta and omega, are used to simulate the hierarchy of leadership. These four wolf groups carry out three main steps: observing and pursuing hunting, approaching and encircling hunting and ultimately hunting attacks. The simplicity and generalizability of problems in large-scale problems are the features of this algorithm.

\subsection{Enhanced Colliding Bodies Optimization}

Enhanced Colliding Bodies Optimization (ECBO) algorithm was proposed by Kaveh and Ilchi Ghazaan [23]. This algorithm is an improved version of the CBO algorithm developed based on the technique of collision of moving objects together and moving toward minimizing energy levels. The use of the memory concept to save the best results obtained so far and using the escape mechanism from local search are the features of this algorithm. Some advantages of using this algorithm to the standard version of $\mathrm{CBO}$ are providing better results, higher convergence rate and more reliable answers. 


\subsection{Salp Swarm Algorithm}

Salp Swarm Algorithm (SSA) was developed by Mirjalili et al. [22]. SSA is adopted by simulating the behavior of the salps that lives in deep oceans, and in particular the formation of a chain-shaped model by them. This chain consists of two parts, the leader who is at the initial position of the chain and the other salps who follow the leader. This algorithm provides a new kind of PSO algorithm based on the chaining behavior of the salps. The benefits of this algorithm to help to solve optimization problems are also applicable to uni-modal and multi-modal functions.

\subsection{Grasshopper Optimisation Algorithm}

Grasshopper Optimisation Algorithm (GOA) was first introduced by Saremi et al. [24]. GOA is based on the grasshoppers search process for finding food that is used to create a mathematical model. This process consists of two parts, the exploration and exploitation process, which represent global and local search, respectively. The feature of this metaheuristic algorithm is the lack of any gradient information from the search space. This algorithm solves the optimization problem as a black box. Also, the initial random population can be improved by this algorithm.

\subsection{Harmony Search}

Harmony Search (HS) algorithm was developed by Geem et al. [21]. HS is extracted from modeling and simulating a process that a composer tracks to harmonize a piece of music. In this algorithm, finding a good and suitable harmony for a music is considered as the process of finding a global and desirable solution to the optimization problem. Less mathematical requirements, low parameters and easy implementation, utilizing all existing solutions in memory and having a simple concept are the features of this algorithm.

\section{Design examples}

In this study, a two-dimensional design example of the symmetric steel curved roof frame for optimization is considered by seven efficient metaheuristic algorithms.

In the design of industrial structures due to the repetition of frames and their identical distances, the design is mostly done for one frame with a two-dimensional method [38]. For the best, mean and the worst optimum weight of the steel curved roof frame, the performance of the EVPS algorithm is compared with six other efficient metaheuristic algorithms including VPS, GWO, HS, SSA, ECBO, and GOA. Matlab codes for many recent metaheuristic algorithms can be found in Kaveh and Bakhshpoori [39]. The optimization algorithms compared in this research, as well as all stages of frame analysis and design are coded in MATLAB ${ }^{\circledR}$ software. The curved roof frame has the geometrical specification as shown in Fig. 8 and Table 5 . Considering $16.0 \mathrm{~m}$ as the width of the frame span, $6.0 \mathrm{~m}$, $1.502 \mathrm{~m}$ and $7.502 \mathrm{~m}$ as the eave height, rise height and ridge height, respectively. The center distance to the center of curved roof frames is $6 \mathrm{~m}$ for the load width of the frame. It is assumed that the two rafters of the frame in the middle of their length and in the direction of the minor axis, have lateral bracing. Base plate connections for columns have been considered as pin-jointed. Rafters and columns of curved roof frames have web tapered steel I-shaped sections. The geographical location of the curved roof frame is in Clay County in Kansas in the United States.

In this article, 18 design variables are defined, which 17 variables are defined as discrete variables. These variables are shown in Fig. 7. The values of these variables (in centimeters) are as follows:

$$
\begin{aligned}
& \text { set } 1=\{0.4,0.5,0.6,0.8,1,1.2,1.5,2,3\} \\
& \text { set } 2=\{15,20,25,30,35,40,45\} \\
& \text { set } 3=\{15,20,25, \ldots, 110,115,120\}
\end{aligned}
$$

The thickness of the flanges and web sections are chosen from set 1 , the flange width of the sections is chosen from set 2, and the web height of the sections is chosen from set 3. For factual usages, the flange thicknesses selected should be equal or bigger than the web thicknesses in all section members. In the process of designing sections of frame elements, this item has also been considered. The last variable is the roof slope angle of the steel curved roof frames. This variable is shown in Figs. 1, 2, 8 and 9. The roof slope angle is defined as the slope of the tangent line on the

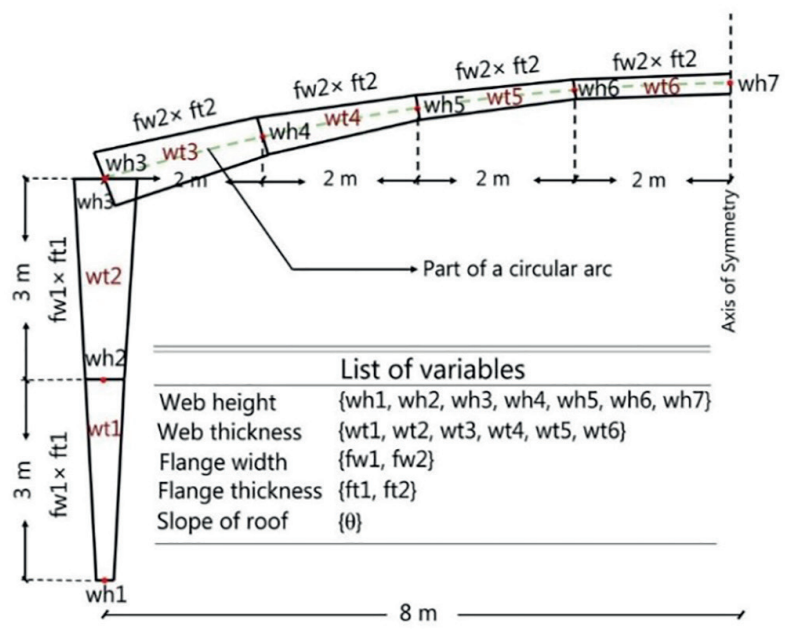

Fig. 7 The considered variables 


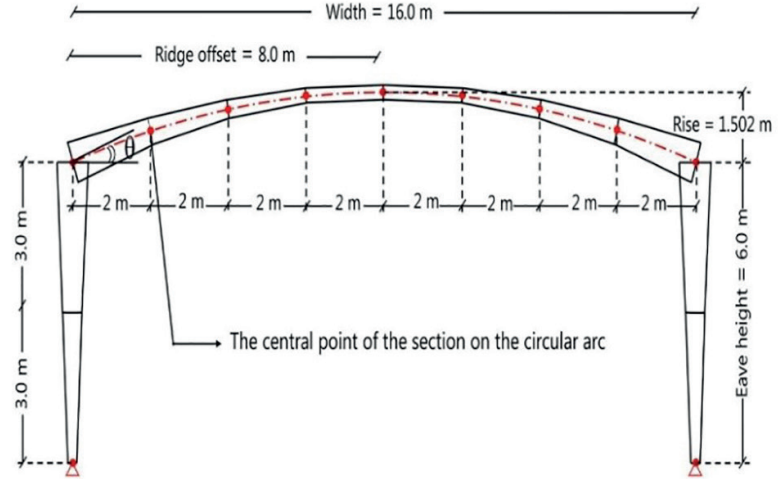

Fig. 8 The geometrical shape of the example building

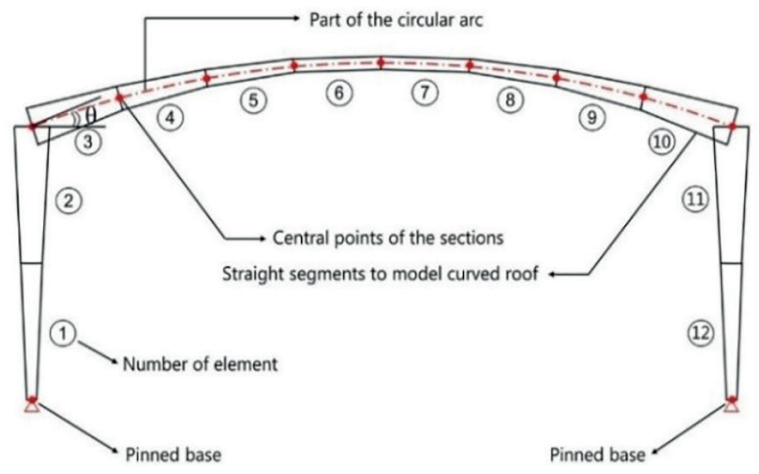

Fig. 9 An idealized model of the steel curved roof frame

circular arc of the roof at the eave point. The range of slope angle of curved roof frames is continuously considered from 3 to 70 degrees. Central points of all sections at the beginning and at the end of the constituent elements of the roof are put on a circular arc. In order to achieve the optimal design, the problem is evaluated by seven algorithms with 30 independent runs contains of 60 population size and 500 iterations. In Tables 6 and 7, the optimum value of the variables for the best optimum design and complementary results for each algorithm are presented, respectively. According to Table 6, the weights and roof slope angles of the steel curved roof frame for the best design are in the range of 1107.1 to $1134 \mathrm{~kg}$ and 13.911 to 21.558 degrees, respectively. In Table 7, the complementary results of utilized algorithms in the optimization process are presented for the best, average and worst weight and their ratios. All of the obtained models for curved roof frames satisfy the intended design constraints. The best optimal weights for all algorithms are compared in Fig. 11. There is a difference of $0.2-2.4 \%$ in the best optimum weights. The best optimal weights are related to GWO, EVPS, ECBO, VPS, GOA, HS and SSA algorithms, respectively. In Fig. 12, the average optimal weight of 30 independent runs by each algorithm is compared. There is a difference of $2.1-11 \%$ in the mean weights. As shown in this diagram, the best mean optimal weights are related to GWO, EVPS, ECBO, VPS, HS, GOA and SSA algorithms, respectively. This diagram shows that the algorithms SSA and GOA have not good result among the selected algorithms. Fig. 10 indicates the comparison of the convergence histories in the best optimum design of utilized algorithms. The GWO and EVPS algorithms have achieved a better design with good relative convergence rates.

Table 8 presents the results of a conventional pitched roof frame with the same span length and different height into present study [4], the weight of a conventional pitched roof frame is higher than the curved roof frame. However, the conditions are not exactly the same for both frames.

Table 5 The geometrical information of building shape for the roof slope angle equal to $21.26^{\circ}$

\begin{tabular}{lc}
\hline Width & $16 \mathrm{~m}$ \\
Length & $36 \mathrm{~m}$ \\
Bay spanning & $6 @ 6 \mathrm{~m}$ \\
Load width of the frame & $6 \mathrm{~m}$ \\
Roof slope angle & 21.26 degree \\
Ridge offset & $8 \mathrm{~m}$ \\
Eave height & $6 \mathrm{~m}$ \\
Rise height & $1.502 \mathrm{~m}$ \\
Mean roof height & $6.751 \mathrm{~m}$ \\
Ridge height & $7.502 \mathrm{~m}$ \\
\hline
\end{tabular}

Table 6 Best value of the variables for optimum design of the steel curved roof frame

\begin{tabular}{|c|c|c|c|c|c|c|c|c|c|c|c|c|c|c|c|c|c|c|c|}
\hline $\begin{array}{l}\text { Metaheuristics } \\
\text { algorithm }\end{array}$ & $\begin{array}{l}\text { wh1 } \\
(\mathrm{cm})\end{array}$ & $\begin{array}{l}\text { wh2 } \\
(\mathrm{cm})\end{array}$ & $\begin{array}{l}\text { wh3 } \\
(\mathrm{cm})\end{array}$ & $\begin{array}{l}\text { wh4 } \\
(\mathrm{cm})\end{array}$ & $\begin{array}{l}\text { wh5 } \\
(\mathrm{cm})\end{array}$ & $\begin{array}{l}\text { wh6 } \\
(\mathrm{cm})\end{array}$ & $\begin{array}{l}\text { wh7 } \\
(\mathrm{cm})\end{array}$ & $\begin{array}{l}\mathrm{wt1} \\
(\mathrm{cm})\end{array}$ & $\begin{array}{l}\mathrm{wt} 2 \\
(\mathrm{~cm})\end{array}$ & $\begin{array}{l}\mathrm{wt3} \\
(\mathrm{cm})\end{array}$ & $\begin{array}{l}\mathrm{wt} 4 \\
(\mathrm{~cm})\end{array}$ & $\begin{array}{l}\mathrm{wt5} \\
(\mathrm{cm})\end{array}$ & $\begin{array}{l}\text { wt6 } \\
(\mathrm{cm})\end{array}$ & $\begin{array}{l}\text { fw1 } \\
(\mathrm{cm})\end{array}$ & $\begin{array}{l}\mathrm{ft} 1 \\
(\mathrm{~cm})\end{array}$ & $\begin{array}{l}\text { fw2 } \\
(\mathrm{cm})\end{array}$ & $\begin{array}{l}\mathrm{ft} 2 \\
(\mathrm{~cm})\end{array}$ & $\begin{array}{c}\text { Roof } \\
\text { slope } \\
\text { angle } \\
\text { (degree) }\end{array}$ & $\begin{array}{c}\text { Best } \\
\text { weight } \\
(\mathrm{kg})\end{array}$ \\
\hline GWO & 15 & 35 & 90 & 40 & 40 & 35 & 45 & 0.4 & 0.4 & 0.5 & 0.4 & 0.4 & 0.4 & 25 & 0.8 & 20 & 0.6 & 21.259 & 1107.1 \\
\hline EVPS & 15 & 35 & 90 & 40 & 40 & 35 & 45 & 0.4 & 0.4 & 0.5 & 0.4 & 0.4 & 0.4 & 25 & 0.8 & 20 & 0.6 & 21.259 & 1107.1 \\
\hline ECBO & 20 & 35 & 90 & 40 & 35 & 40 & 50 & 0.4 & 0.4 & 0.5 & 0.4 & 0.4 & 0.4 & 25 & 0.8 & 20 & 0.6 & 16.391 & 1109.0 \\
\hline VPS & 15 & 35 & 90 & 45 & 35 & 35 & 50 & 0.4 & 0.4 & 0.5 & 0.4 & 0.4 & 0.4 & 25 & 0.8 & 20 & 0.6 & 21.558 & 1111.5 \\
\hline GOA & 20 & 35 & 85 & 40 & 35 & 45 & 70 & 0.4 & 0.4 & 0.5 & 0.4 & 0.4 & 0.4 & 25 & 0.8 & 20 & 0.6 & 13.911 & 1116.7 \\
\hline HS & 15 & 40 & 90 & 45 & 30 & 40 & 50 & 0.4 & 0.4 & 0.5 & 0.4 & 0.4 & 0.4 & 20 & 1 & 20 & 0.6 & 20.214 & 1127.9 \\
\hline SSA & 15 & 40 & 80 & 30 & 60 & 70 & 95 & 0.4 & 0.5 & 0.5 & 0.4 & 0.4 & 0.4 & 20 & 0.8 & 20 & 0.6 & 17.93 & 1134.0 \\
\hline
\end{tabular}


Table 7 Complementary weight results of the optimization algorithms

\begin{tabular}{lccccc}
\hline $\begin{array}{l}\text { Metaheuristic } \\
\text { algorithms }\end{array}$ & $\begin{array}{c}\text { Best weight } \\
(\mathrm{kg})\end{array}$ & $\begin{array}{c}\text { Best weight } \\
\text { ratio }\end{array}$ & $\begin{array}{c}\text { Mean weight } \\
(\mathrm{kg})\end{array}$ & $\begin{array}{c}\text { Mean weight } \\
\text { ratio }\end{array}$ & $\begin{array}{c}\text { Worst weight } \\
(\mathrm{kg})\end{array}$ \\
\hline GWO & 1107.1 & 1 & 1114.3 & 1 & 1165.5 \\
EVPS & $\mathbf{1 1 0 7 . 1}$ & $\mathbf{1}$ & $\mathbf{1 1 3 7 . 6}$ & $\mathbf{1 . 0 2 1}$ & $\mathbf{1 2 1 3 . 2}$ \\
ECBO & 1109 & 1.002 & 1139.1 & 1.022 & 1206.8 \\
VPS & 1111.5 & 1.004 & 1141.8 & 1.025 & 1210.7 \\
GOA & 1116.7 & 1.009 & 1200.9 & 1.077 & 1436.4 \\
HS & 1127.9 & 1.019 & 1167 & 1.046 & 1239.6 \\
SSA & 1134 & 1.024 & 1237.9 & 1.11 & 1475.1 \\
\hline
\end{tabular}

Table 8 Optimum design of a conventional pitched roof frame [4]

\begin{tabular}{|c|c|c|c|c|c|c|c|c|c|c|}
\hline $\begin{array}{l}\text { Case } \\
\text { No. }\end{array}$ & $\begin{array}{l}\text { Surface } \\
\text { No. }\end{array}$ & $\begin{array}{l}\text { Element } \\
\text { type }\end{array}$ & $\begin{array}{c}\text { Element } \\
\text { No. }\end{array}$ & $\begin{array}{l}\text { Start web } \\
\text { height }(\mathrm{m})\end{array}$ & $\begin{array}{c}\text { Flange } \\
\text { width (m) }\end{array}$ & $\begin{array}{l}\text { Inside flange } \\
\text { thickness (m) }\end{array}$ & $\begin{array}{c}\text { Web } \\
\text { thickness (m) }\end{array}$ & $\begin{array}{l}\text { Outside flange } \\
\text { thickness (m) }\end{array}$ & $\begin{array}{l}\text { End web } \\
\text { height }(m)\end{array}$ & $\begin{array}{l}\text { Weight } \\
(\mathrm{kg})\end{array}$ \\
\hline \multirow{5}{*}{1} & \multirow{2}{*}{1} & \multirow{2}{*}{ Column } & 1 & 0.15 & 0.20 & 0.008 & 0.005 & 0.006 & 0.80 & \multirow{5}{*}{1457.2} \\
\hline & & & 2 & 0.80 & 0.20 & 0.008 & 0.005 & 0.006 & 1.20 & \\
\hline & \multirow{3}{*}{2} & \multirow{3}{*}{ Beam } & 3 & 1.2 & 0.15 & 0.010 & 0.006 & 0.01 & 0.85 & \\
\hline & & & 4 & 0.85 & 0.15 & 0.010 & 0.005 & 0.01 & 0.35 & \\
\hline & & & 5 & 0.35 & 0.15 & 0.010 & 0.005 & 0.01 & 1.05 & \\
\hline \multirow{4}{*}{2} & 1 & Column & 1 & 0.35 & 0.25 & 0.008 & 0.005 & 0.008 & 1.10 & \multirow{4}{*}{1477.8} \\
\hline & \multirow{3}{*}{2} & \multirow{3}{*}{ Beam } & 2 & 1.10 & 0.15 & 0.008 & 0.005 & 0.008 & 1.2 & \\
\hline & & & 3 & 1.20 & 0.15 & 0.008 & 0.005 & 0.008 & 0.45 & \\
\hline & & & 4 & 0.45 & 0.15 & 0.008 & 0.005 & 0.008 & 0.30 & \\
\hline \multirow{2}{*}{3} & 1 & Column & 1 & 0.65 & 0.20 & 0.008 & 0.005 & 0.008 & 0.95 & \multirow{2}{*}{1578.4} \\
\hline & 2 & Beam & 2 & 0.95 & 0.25 & 0.008 & 0.005 & 0.008 & 0.30 & \\
\hline
\end{tabular}

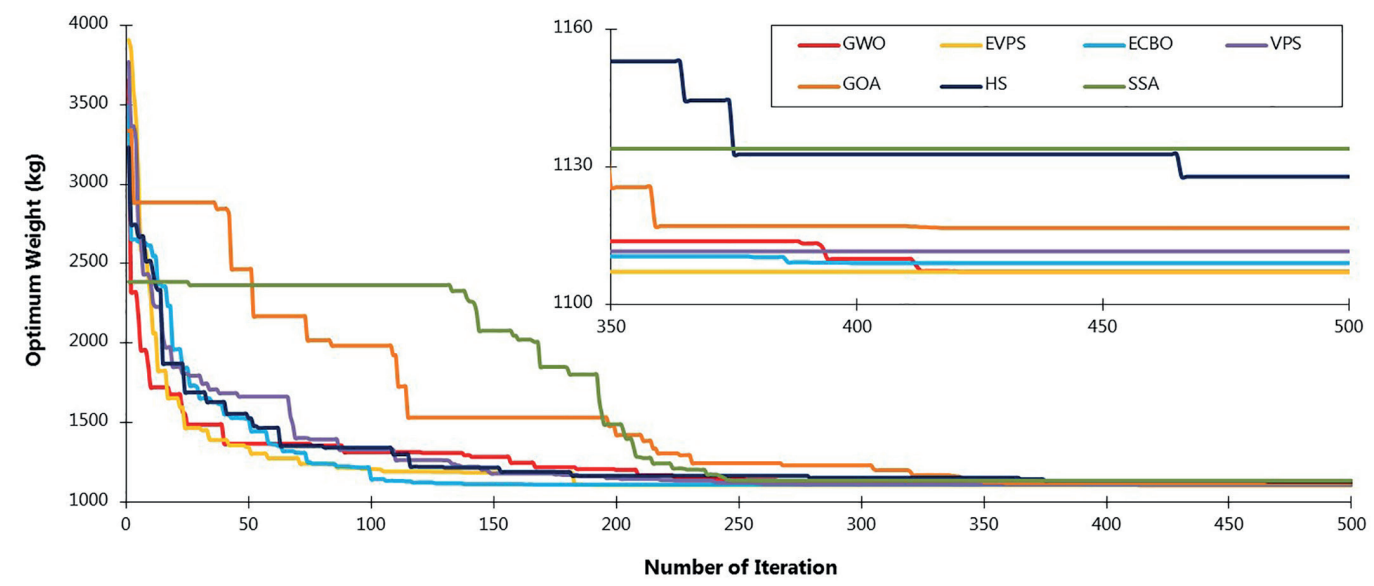

Fig. 10 Comparison of the convergence histories for the best optimum weight of the utilized algorithms

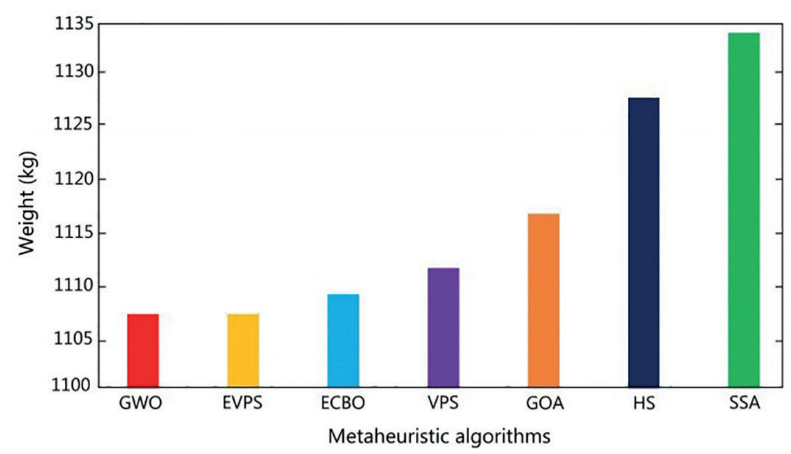

Fig. 11 Best optimal weights obtained from algorithms

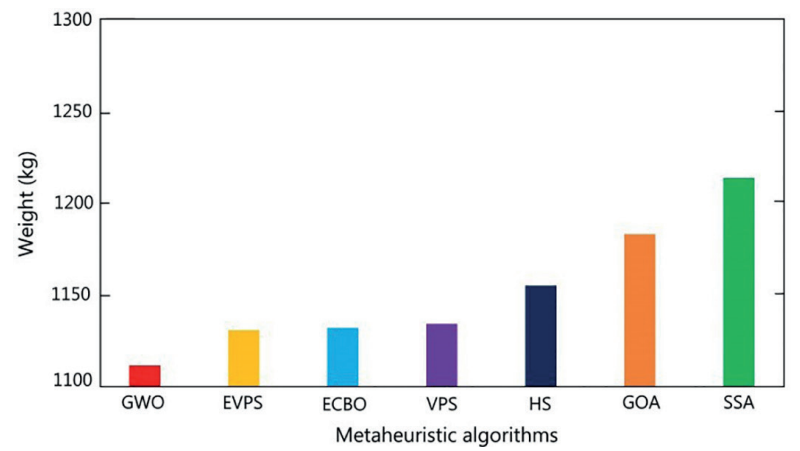

Fig. 12 Mean optimal weights obtained from algorithms 


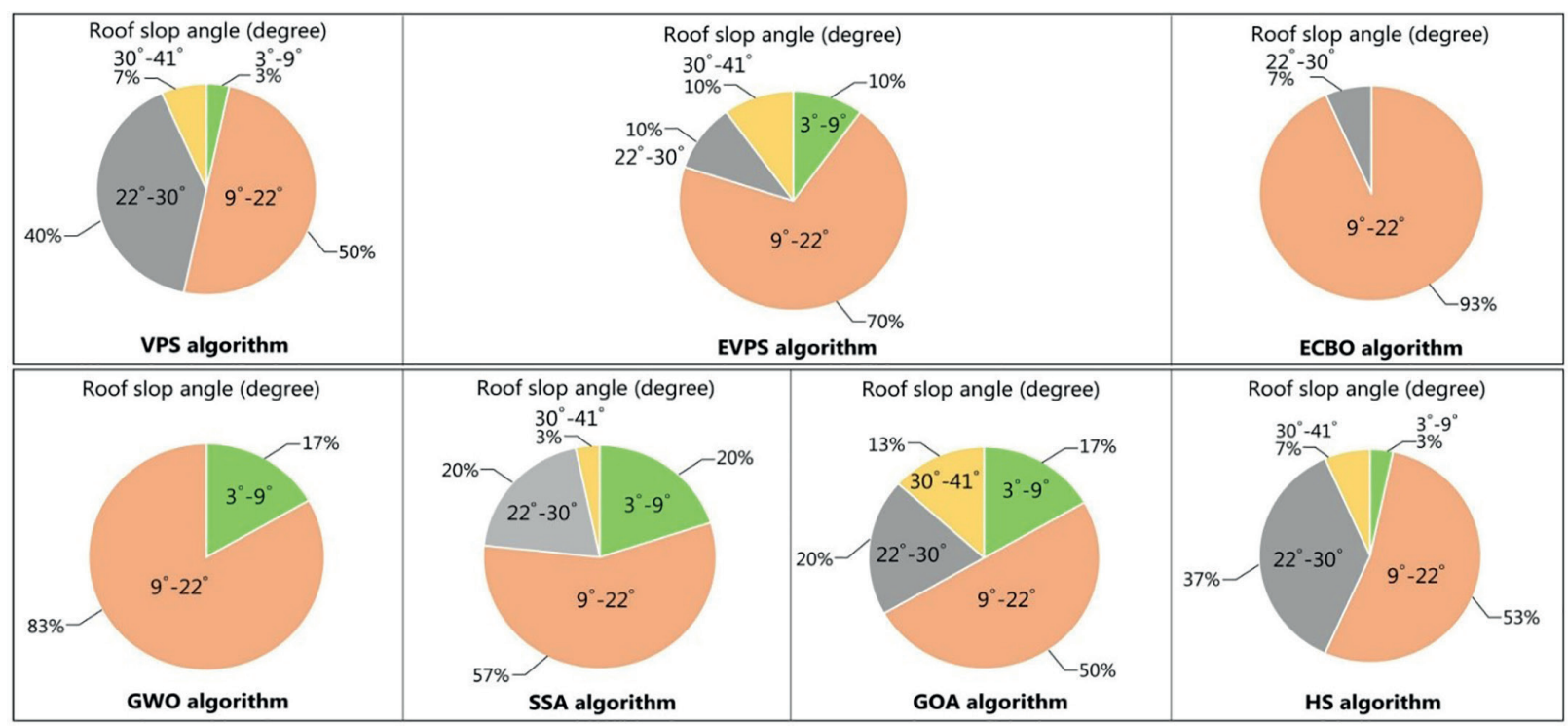

Fig. 13 Roof slope angle dispersion in optimal design for the utilized algorithms

The roof slope angles obtained in the optimization process of steel curved roof frame are divided into four parts according to Fig. 13. As shown in Fig. 13, the maximum roof slope angle dispersion in optimal design for each algorithm is in the range of 9-22 degrees, which is between $50-93 \%$ of the roof slope angles in this range. Fig. 14 shows that $65 \%$ of the roof slope angles in all algorithms have been in this range. Due to the importance of this range, more details of roof slope angle dispersion for the range of 9-22 degrees and for all algorithms are shown in Fig. 14. A comparison of the allowable and existing stresses ratio for best optimum design is shown in Fig. 15. The maximum and minimum existing stress ratio are 0.995 and 0.944 , respectively. The comparison of the allowable and existing nodal displacements for the best design optimized are shown in Table 9. In Fig. 16 the 3-D view of the steel curved roof frame for best optimum design is illustrated in Fig. 16.

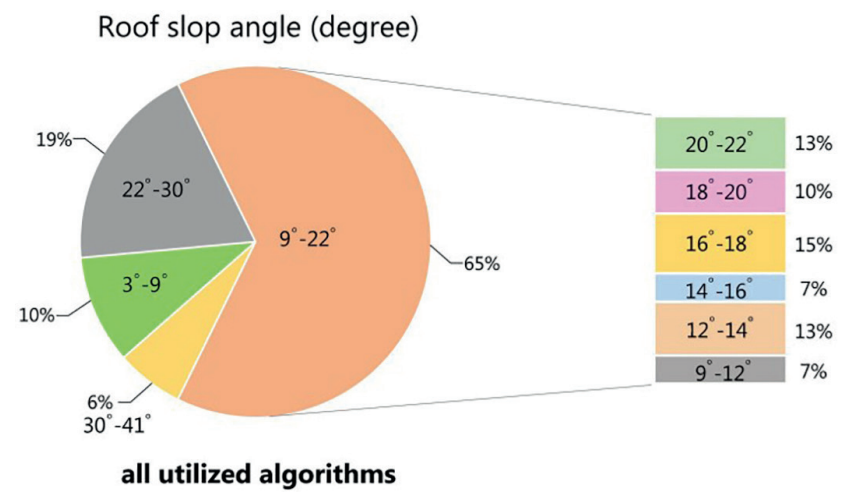

Fig. 14 Roof slope angle dispersion in optimal design for total algorithm

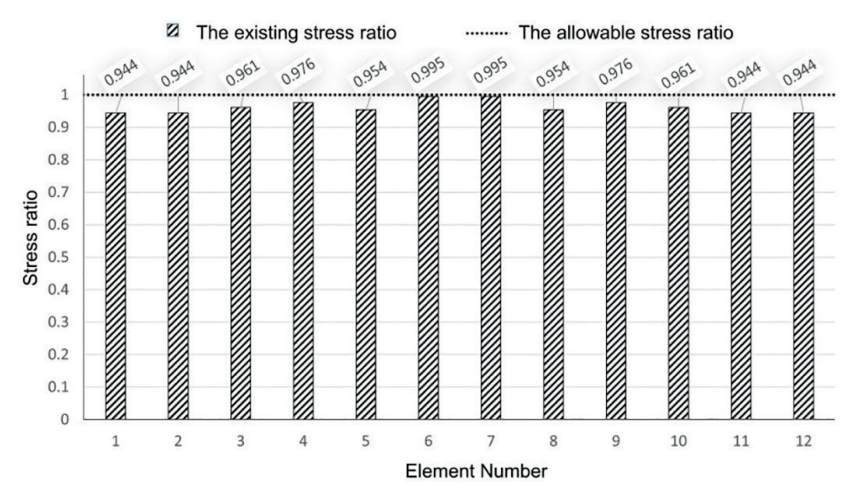

Fig. 15 Comparison of the allowable and existing stress ratios for the best optimum design

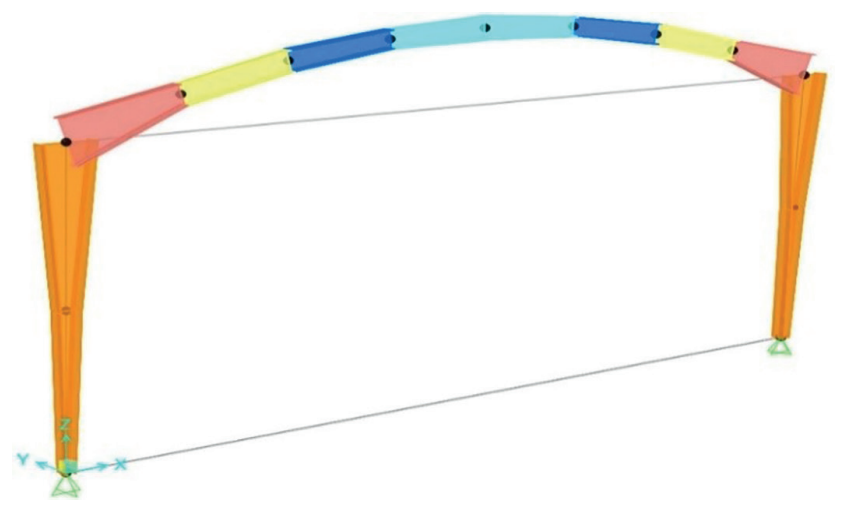

Fig. 16 3-D view of the steel curved roof frame for the best optimum design

\section{Discussion and conclusions}

An efficient procedure for the optimal design of steel curved roof frames with tapered members, based on Enhanced Vibrating Particles System (EVPS) algorithms and a comparative study with six recently developed metaheuristic algorithms including VPS, GWO, HS, SSA, ECBO and 
Table 9 Comparison of the allowable and existing nodal displacement for the best optimum design

\begin{tabular}{lcc}
\hline Nodal displacement & $\begin{array}{c}\text { Allowable } \\
\text { displacement } \\
(\mathrm{mm})\end{array}$ & $\begin{array}{c}\text { Existing } \\
\text { displacement } \\
(\mathrm{mm})\end{array}$ \\
\hline $\begin{array}{l}\text { The maximum drift of left eave } \\
\text { point under lateral load }\end{array}$ & 30 & 30 \\
$\begin{array}{l}\text { The maximum drift of right eave } \\
\text { point under lateral load }\end{array}$ & 30 & 23.5 \\
$\begin{array}{l}\text { The maximum deflection of apex } \\
\text { under dead load }\end{array}$ & 44.4 & 6.5 \\
$\begin{array}{l}\text { The maximum deflection of apex } \\
\text { under live load }\end{array}$ & 66.67 & 31.88 \\
\hline
\end{tabular}

GOA algorithms has been proposed in this study. In order to find the optimum weight of the frame, the cross-section sizes at the beginning and the end of the constitutive elements of the rafters and columns also the roof slope angle of steel curved roof frames are considered as optimization variables. Then, the appropriate roof slope angle and cross-section sizes by considered algorithms are selected respectively from continuous and discrete variables in the optimization process.

The proximity of the maximum and minimum existing stress ratio for the frame elements which are equal to 0.995 and 0.944 respectively, shows the high efficiency of the proposed method for the optimal design of steel curved roof frames. Furthermore, the proposed method has good speed to achieve an optimal design.

\section{References}

[1] Fraser, D. J. "Design of tapered member portal frames", Journal of Constructional Steel Research, 3(3), pp. 20-26, 1983. https://doi.org/10.1016/0143-974X(83)90003-2

[2] Kim, Y. D. "Behavior and design of metal building frames using general prismatic and web-tapered steel I-section members", Doctoral dissertation, Georgia Institute of Technology, 2010. [online] Available at: http://hdl.handle.net/1853/33965 [Accessed: 10 August 2019]

[3] Ziemian, R. D. "Guide to stability design criteria for metal structures", 6th ed., John Wiley and Sons, Hoboken, NJ, USA, 2010. https://doi.org/10.1002/9780470549087

[4] Kaveh, A., Mahdavi, V. R., Kamalinejad, M. "Optimal design of pitched roof frames with tapered members using ECBO algorithm", Smart Structures and Systems, 19(6), pp. 643-652, 2017. https://doi.org/10.12989/sss.2017.19.6.643

[5] Kaveh, A. "Advances in Metaheuristic Algorithms for Optimal Design of Structures", 2nd ed., Springer, Basel, Switzerland, 2017. https://doi.org/10.1007/978-3-319-46173-1

[6] Saka, M. P. "Optimum design of pitched roof steel frames with haunched rafters by genetic algorithm", Computers and Structures, 81(18-19), pp. 1967-1978, 2003.
Generally, the results of the performance of the EVPS algorithms, compared to the other metaheuristic algorithms including VPS, GWO, HS, ECBO, SSA, and GOA algorithms to solve the problem, indicate that EVPS algorithm has better performance than other algorithms except for GWO. Although the EVPS and GWO algorithms have the same results in the best optimum weight of steel curved roof frame.

The range defined for the optimization variable of roof slope angle has been continuously from 3 to 70 degrees. The optimum results obtained from all algorithms show that 65 percent of roof slope angle values for the steel curved roof frames was between 9 to 22 degrees in total runs. Therefore, this range can be known as the optimum range of roof slope angle for the problem. Among this optimal range, the angles from 16 to 18 degrees have the most repetition in accordance with Fig. 14. However, the best answer to the problem is obtained for the roof slope angle near 21 degrees.

Among the chosen design constraints, the horizontal displacement of the pitched roof steel frame, it has reached earlier than the other design constraints equal to its allowable capacity. Therefore, the horizontal displacement constraint is one of the most important constraints and a determining factor in the optimal design of pitched roof steel frames. Future research can include finding the optimum roof slope angle for the different span lengths of steel curved roof frame and the presentation of the graph using recently developed metaheuristic optimization algorithms.

https://doi.org/10.1016/S0045-7949(03)00216-5

[7] Kravanja, S., Žula, T. "Cost optimization of industrial steel building structures", Advances in Engineering Software, 41(3), pp. 442-450, 2010.

https://doi.org/10.1016/j.advengsoft.2009.03.005

[8] Kravanja, S., Turkalj, G., Šilih, S., Žula, T. "Optimal design of single-story steel building structures based on parametric MINLP optimization", Journal of Constructional Steel Research, 81, pp. 86-103, 2013.

https://doi.org/10.1016/j.jcsr.2012.11.008

[9] McKinstray, R., Lim, J. B., Tanyimboh, T. T., Phan, D. T., Sha, W. "Optimal design of long-span steel portal frames using fabricated beams", Journal of Constructional Steel Research, 104, pp. 104114, 2015.

https://doi.org/10.1016/j.jcsr.2014.10.010

[10] McKinstray, R., Lim, J. B., Tanyimboh, T. T., Phan, D. T., Sha, W. "Comparison of optimal designs of steel portal frames including topological asymmetry considering rolled, fabricated and tapered sections", Engineering Structures, 111, pp. 505-524, 2016. https://doi.org/10.1016/j.engstruct.2015.12.028 
[11] Kaveh, A., Kabir, M. Z., Bohlool, M. "Optimal Design of MultiSpan Pitched Roof Frames with Tapered Members", Periodica Polytechnica Civil Engineering, 63(1), pp. 77-86, 2019.

https://doi.org/10.3311/PPci.13107

[12] Arzani, H., Kaveh, A., Kamalinejad, M. "Optimal Design of Pitched Roof Rigid Frames with Non-Prismatic Members Using Quantum Evolutionary Algorithm", Periodica Polytechnica Civil Engineering, 63(2), pp. 593-607, 2019. https://doi.org/10.3311/PPci.14091

[13] King, C., Brown, D. "Design of Curved Steel", 1st ed., The Steel Construction Institute Silwood Park, Ascot, UK, 2001.

[14] Vanderplaats, G. N., Han, S. H. "Arch shape optimization using force approximation methods", Structural and Multidisciplinary Optimization, 2(4), pp. 193-201, 1990. https://doi.org/10.1007/BF01748223

[15] Tayşi, N., Göğüş, M. T., Özakça, M. "Optimization of arches using genetic algorithm", Computational Optimization and Applications, 41(3), pp. 377-394, 2008. https://doi.org/10.1007/s10589-007-9111-3

[16] AISC "AISC 360-05 Specification for Structural Steel Buildings", American Institute of Steel Construction, Chicago, IL, USA, 2005.

[17] ASCE "ASCE/SEI 7-10 Minimum Design Loads for Buildings and Other Structures", American Society of Civil Engineers, Reston, Virginia, USA, 2015.

[18] Kaveh, A., Hoseini Vaez, S. R., Hosseini, P. "Enhanced vibrating particles system algorithm for damage identification of truss structures", Scientia Iranica, 26(1), pp. 246-256, 2019. https://doi.org/10.24200/SCI.2017.4265

[19] Kaveh, A., Ilchi Ghazaan, M. "Vibrating particles system algorithm for truss optimization with multiple natural frequency constraints", Acta Mechanica, 228(1), pp. 307-322, 2017. https://doi.org/10.1007/s00707-016-1725-z

[20] Mirjalili, S., Mirjalili, S. M., Lewis, A. "Grey Wolf Optimizer", Advances in Engineering Software, 69, pp. 46-61, 2014. https://doi.org/10.1016/j.advengsoft.2013.12.007

[21] Geem, Z. W., Kim, J. H., Loganathan, G. V. "A New Heuristic Optimization Algorithm: Harmony Search", Simulation, 76(2), pp. 60-68, 2001.

https://doi.org/10.1177/003754970107600201

[22] Mirjalili, S., Gandomi, A. H., Mirjalili, S. Z., Saremi, S., Faris, H., Mirjalili, S. M. "Salp Swarm Algorithm: A bio-inspired optimizer for engineering design problems", Advances in Engineering Software, 114, pp. 163-191, 2017.

https://doi.org/10.1016/j.advengsoft.2017.07.002

[23] Kaveh, A., Ilchi Ghazaan, M. "Enhanced colliding bodies optimization for design problems with continuous and discrete variables", Advances in Engineering Software, 77, pp. 66-75, 2014. https://doi.org/10.1016/j.advengsoft.2014.08.003

[24] Saremi, S., Mirjalili, S., Lewis, A. "Grasshopper Optimisation Algorithm: Theory and Application", Advances in Engineering Software, 105, pp. 30-47, 2017. https://doi.org/10.1016/j.advengsoft.2017.01.004

[25] AISC "AISC 360-10 Specification for Structural Steel Buildings", Chicago, IL, USA, 2010
[26] Nazari-Heris, M., Mehdinejad, M., Mohammadi-Ivatloo, B., Babamalek-Gharehpetian, G. "Combined heat and power economic dispatch problem solution by implementation of whale optimization method", Neural Computing and Applications, 31(2), pp. 421-436, 2019. https://doi.org/10.1007/s00521-017-3074-9

[27] Zhao, Y., Noorbakhsh, A., Koopialipoor, M., Azizi, A., Tahir, M. M. "A new methodology for optimization and prediction of rate of penetration during drilling operations", Engineering with Computers, 2019. https://doi.org/10.1007/s00366-019-00715-2

[28] Sameer, F. O., Abu Bakar, M. A., Zaidan, A. A., Zaidan, B. B. "A new algorithm of modified binary particle swarm optimization based on the Gustafson-Kessel for credit risk assessment", Neural Computing and Applications, 31(2), pp. 337-346, 2019. https://doi.org/10.1007/s00521-017-3018-4

[29] Reddy, K. S., Panwar, L., Panigrahi, B. K., Kumar, R. "Binary whale optimization algorithm: a new metaheuristic approach for profit-based unit commitment problems in competitive electricity markets", Engineering Optimization, 51(3), pp. 369-389, 2019. https://doi.org/10.1080/0305215X.2018.1463527

[30] Stützle, T., López-Ibáñez, M. "Automated Design of Metaheuristic Algorithms", In: Gendreau, M., Potvin, J.-Y. (eds.) Handbook of Metaheuristics, Springer, Cham, Switzerland, 2018, pp. 541-579. https://doi.org/10.1007/978-3-319-91086-4_17

[31] Pijarski, P., Kacejko, P. "A new metaheuristic optimization method: the algorithm of the innovative gunner (AIG)", Engineering Optimization, 2019. https://doi.org/10.1080/0305215X.2019.1565282

[32] Yapici, H., Cetinkaya, N. "A new meta-heuristic optimizer: Pathfinder algorithm", Applied Soft Computing, 78, pp. 545-568, 2019. https://doi.org/10.1016/j.asoc.2019.03.012

[33] Dede, T., Grzywiński, M., Rao, R. V. "Jaya: A New Meta-heuristic Algorithm for the Optimization of Braced Dome Structures", In: Advanced Engineering Optimization Through Intelligent Techniques, Select Proceedings of AEOTIT 2018, Singapore, 2020, pp. 13-20. https://doi.org/10.1007/978-981-13-8196-6_2

[34] Grzywiński, M., Dede, T., Ozdemir, Y. I. "Optimization of the braced dome structures by using Jaya algorithm with frequency constraints", Steel and Composite Structures, 3(1), pp. 47-55, 2019. https://doi.org/10.12989/scs.2019.30.1.047

[35] Kaveh, A., Hoseini Vaez, S. R., Hosseini, P. "Performance of the Modified Dolphin Monitoring Operator for Weight Optimization of Skeletal Structures", Periodica Polytechnica Civil Engineering, 63(1), pp. 30-45, 2019. https://doi.org/10.3311/PPci.12544

[36] Kaveh, A., Hoseini Vaez, S. R., Hosseini, P. "Modified Dolphin Monitoring Operator for Weight Optimization of Frame Structures", Periodica Polytechnica Civil Engineering, 61(4), pp. 770-779, 2017. https://doi.org/10.3311/PPci.9691

[37] Kaveh, A., Ilchi Ghazaan, M. "Enhanced whale optimization algorithm for sizing optimization of skeletal structures", Mechanics Based Design of Structures and Machines, 45 (3), pp. 345-362, 2017. https://doi.org/10.1080/15397734.2016.1213639 
[38] Kaveh, A., Ghafari, M. H. "Geometry and Sizing Optimization of Steel Pitched Roof Frames with Tapered Members Using Nine Metaheuristics", Iranian Journal of Science and Technology, Transactions of Civil Engineering, 43(1), 2019. https://doi.org/10.1007/s40996-018-0132-1
[39] Kaveh, A., Bakhshpoori, T. "Metaheuristics: Outlines, MATLAB Codes and Examples", 1st ed., Springer, Cham, Switzerland, 2019. https://doi.org/10.1007/978-3-030-04067-3 